Available online at https://jurnal.stmikroyal.ac.id/index.php/jurdimas

\title{
IMPLEMENTASI PENGGUNAAN PERALATAN KESELAMATAN PELAYARAN KAWASAN DANAU TOBA
}

\author{
Dafid Ginting $^{*}$, Yuris Danilwan ${ }^{2}$, Netty Kesuma ${ }^{2}$, Yuna Sutria ${ }^{2}$, Fatolosa \\ Telaoembanoea ${ }^{3}$. \\ ${ }^{1}$ Nautika, Akademi Maritim Indonesia (AMI) Medan \\ ${ }^{2}$ KPNK, Akademi Maritim Indonesia (AMI) Medan \\ ${ }^{3}$ Teknika, Akademi Maritim Indonesia (AMI) Medan \\ email: dafidginting@ amimedan.ac.id
}

\begin{abstract}
The re-occurrence of the ship accident while sailing in Toba Lake shows that the operational standard procedure (SOP) on safety and security issues, which are then followed by affordable cost aspects, speed and timeliness, and convenience aspects have not been implemented effectively and maximally. Therefore the proponent team from the Indonesian Maritime Academy College in Medan proposed community service activities in the form of training and mentoring for target partners to provide scientific education along with the assistance of partner education facilities. The results of this activity are published in scientific journals, electronic mass media. In addition, the activity videos and the improvement of the knowledge and skills of partner HR are outcomes of this activity. The lecture and demonstration methods used in the process provide an understanding of the use of shipping safety equipment. The practice method is directly used to skill in using shipping safety equipment, of course, with the assistance of the proposing team. Observation method is done to observe the ability of partners both during the activity process and afterwards. Observation after the activity is intended to determine the impact of the activities that have been carried out.
\end{abstract}

Keywords: standard operating procedures, Toba lake, shipping safety equipment

\begin{abstract}
Abstrak: Terjadinya kembali musibah kecelakaan kapal saat berlayar di Danau Toba menunjukkan bahwa standar operasional prosedur (SOP) persoalan keselamatan dan keamanan, yang selanjutnya baru diikuti dengan aspek biaya yang terjangkau, kecepatan dan ketepatan waktu, serta aspek kenyamanan belum dilaksanakan secara efektif dan maksimal. Oleh sebab itu tim pengusul yang berasal dari Perguruan Tinggi Akademi Maritim Indonesia Medan mengusulkan kegiatan pengabdian kepada masyarakat dalam bentuk pelatihan dan pendampingan terhadap mitra sasaran untuk memberikan edukasi ilmiah disertai dengan adanya bantuan sarana edukasi mitra. Hasil dari kegiatan ini dipublikasikan di jurnal ilmiah, media massa elektronik. Selain itu video kegiatan serta peningkatan pengetahuan dan keterampilan SDM mitra merupakan luaran dari kegiatan ini. Metode ceramah dan demonstrasi digunakan dalam proses memberikan pemahaman mengenai penggunaan peralatan keselamatan pelayaran. Metode praktik langsung digunakan untuk keterampilan menggunakan peralatan keselamatan pelayaran tentunya dengan pendampingan tim pengusul. Metode observasi dilakukan untuk mengamati kemampuan mitra baik selama proses kegiatan maupun sesudahnya. Evaluasi sesudah kegiatan ditujukan untuk mengetahui dampak dari kegiatan yang telah dilaksanakan.
\end{abstract}

Kata kunci: standar operasional prosedur, danau toba, peralatan keselamatan pelayaran 
Jurdimas (Jurnal Pengabdian Kepada Masyarakat) Royal

Vol. 2 No. 1, Jan 2019, hlm. 33 - 38

DOI: https://doi.org/10.33330/jurdimas.v2i1.283

ISSN 2614-7912 (Print)

Available online at https://jurnal.stmikroyal.ac.id/index.php/jurdimas

\section{PENDAHULUAN}

Perahu motor merupakan salah satu jenis transportasi perairan yang sering digunakan masyarakat Indonesia terutama untuk menuju suatu lokasi pulau yang letaknya berada jauh dari daratan luas. Perahu motor juga merupakan salah satu armada kapal yang membuktikan dirinya sebagai sarana transportasi laut yang tangguh, identik dengan usaha ekonomi kerakyatan berbasis perahu tradisional yang memakai motor penggerak. Hingga kini, armada pelayaran rakyat merupakan salah satu kekuatan armada nasional disamping armada pelayaran nusantara dan pelayaran perintis lainnya. Unsur keselamatan merupakan salah satu mata rantai, yang memberi pengaruh sangat besar pada ekonomi dari keseluruhan rantai usaha transportasi laut Akan tetapi seringkali dalam penyelenggaraan transportasi laut aspek keselamatan kurang mendapat perhatian.

Berdasarkan hasil observasi dan interview yang dilakukan tim pengusul Akademi Maritim Indonesia Medan terhadap masyarakat di daerah Pelabuhan Tigaras, Kecamatan Dolok Pardamean, Kabupaten Simalungun, diketahui bahwa kemampuan dalam berlayar yang dimiliki oleh nelayan ataupun nakhoda kapal diperoleh secara turun - temurun dari orangtuanya. Kemampuan tersebut sudah digeluti semenjak sekolah di tingkat SD. karena pekerjaan menetap ayahnya sebagai nelayan dan selalu melibatkan anaknya untuk berlayar mencari ikan sebelum berangkat sekolah di pagi hari. Hal inilah yang menjadikan masyarakat yang menekuni dunia pelayaran di Danau Toba tidak memiliki pengetahuan yang mendasar untuk berlayar termasuk keselamatan selama berlayar. Oleh sebab itu tim pengusul mengunjungi sekolah SMA Negeri 1 Dolok Pardamean untuk melakukan survey pendahuluan sekaligus analisis kebutuhan.

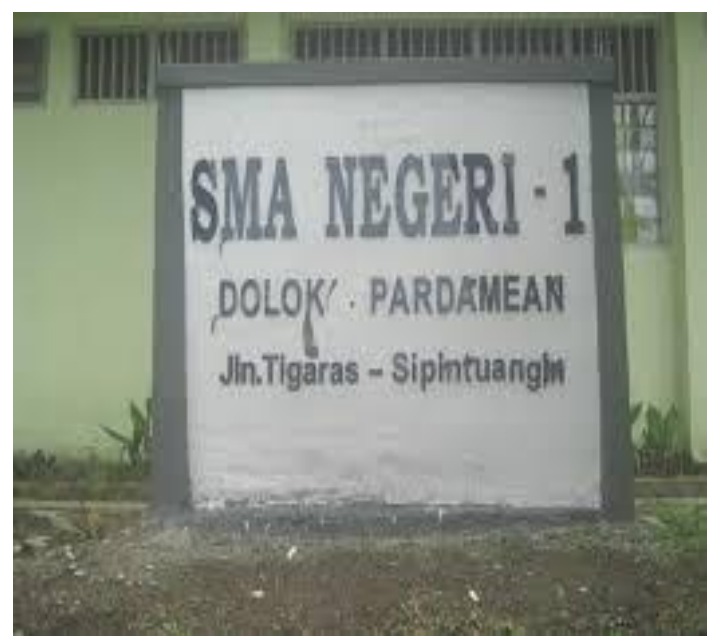

\section{Gambar 1. SMA Negeri 1 Dolok Pardamean}

Pada konteks ini, Akademi Maritim Indonesia Medan berperan secara lebih jauh sebagai lembaga formal perguruan tinggi yang dapat melakukan pelatihan atau pembekalan pengetahuan kepada masyarakat untuk berlayar dengan standar pengetahuan keselamatan berdasarkan kaidah kaidah ilmiah yang akan diterapkan dalam pengabdian masyarakat. Dengan diberikannya pembekalan tentang keselamatan dan keamanan pelayaran terhadap masyarakat diharapkan mampu menurunkan secara drastis jumlah musibah atau kecelakaan kapal. Selain itu hibah safety equipment yang nantinya diberikan juga diharapkan dapat digunakan secara baik dan 
Jurdimas (Jurnal Pengabdian Kepada Masyarakat) Royal

Vol. 2 No. 1, Jan 2019, hlm. 33 - 38

ISSN 2614-7912 (Print)

DOI: https://doi.org/10.33330/jurdimas.v2i1.283

ISSN 2622-3813 (Online)

Available online at https://jurnal.stmikroyal.ac.id/index.php/jurdimas

maksimal untuk keselamatan penumpang kapal sehingga keselamatan dan keamanan pelayaran di sini, adalah kebijakan utama yang harus mendapatkan prioritas pada pelayaran dalam menunjang kelancaran transportasi.

Kegiatan

pengabdian

masyarakat ini dilaksanakan agar siswa yang merupakan anak dari nelayan/nakhoda kapal di Pelabuhan Tigaras yang terjun di pelayaran dapat mengetahui, memahami serta meningkatkan

kemampuan pengetahuan yang mendasar terhadap keselamatan berlayar di Tigaras Kecamatan Dolok Pardamean, Kabupaten Simalungun.

\section{METODE}

Materi pokok kegiatan yang telah dilaksanakan berhubungan dengan peralatan keselamatan transportasi berdasarkan peraturan dalam berlayar serta petunjuk manfaat dan penggunaannya dalam bentuk pelatihan. Pada kegiatan ini, Tim Pengusul kegiatan Pengabdian Kepada Masyarakat Akademi Maritim Indonesia Medan memberikan pengetahuan terhadap mitra dengan cara metode demonstrasi dan ceramah. Kegiatan ini dilakukan didalam ruangan dengan menggunakan tutorial dengan slide dan presentasi. Peralatan pendukung pelatihan ini menggunakan Laptop, infocus dan peralatan keselamatan pelayaran. Tim pengusul yang terlibat dalam kegiatan ini secara bekerjasama melakukan penilaian terhadap mitra dari hasil evaluasi berbentuk tes.

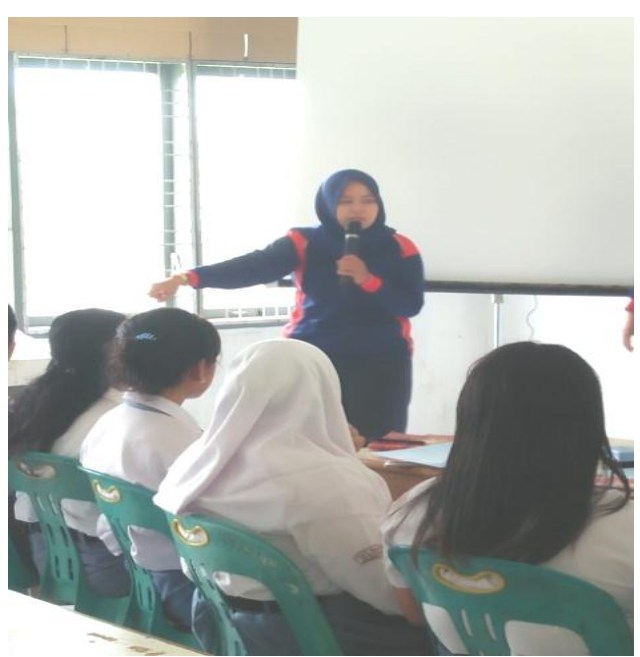

Gambar 2. Memberikan

Pengetahuan Terhadap Keselamatan Berlayar

\section{PEMBAHASAN}

Pada konteks ini, Akademi Maritim Indonesia Medan berperan secara lebih jauh sebagai lembaga formal perguruan tinggi yang dapat melakukan pelatihan atau pembekalan pengetahuan kepada masyarakat untuk berlayar dengan standar pengetahuan keselamatan berdasarkan kaidah kaidah ilmiah yang akan diterapkan dalam pengabdian masyarakat.

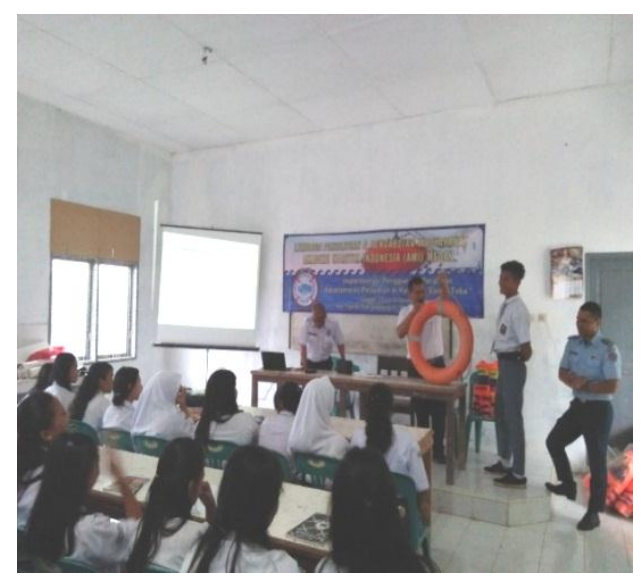

Gambar 3. Arahan dari salah seorang Tim Pengusul 
Jurdimas (Jurnal Pengabdian Kepada Masyarakat) Royal

Vol. 2 No. 1, Jan 2019, hlm. 33 - 38

ISSN 2614-7912 (Print)

DOI: https://doi.org/10.33330/jurdimas.v2i1.283

Available online at https://jurnal.stmikroyal.ac.id/index.php/jurdimas

Pelatihan tentang keselamatan pelayaran ini diharapkan mampu menurunkan secara drastis jumlah musibah atau kecelakaan kapal. Selain itu hibah safety equipment yang diberikan diharapkan dapat digunakan secara baik dan maksimal untuk keselamatan penumpang kapal sehingga keselamatan dan keamanan pelayaran merupakan kebijakan utama yang harus mendapatkan prioritas pada pelayaran dalam menunjang kelancaran transportasi.

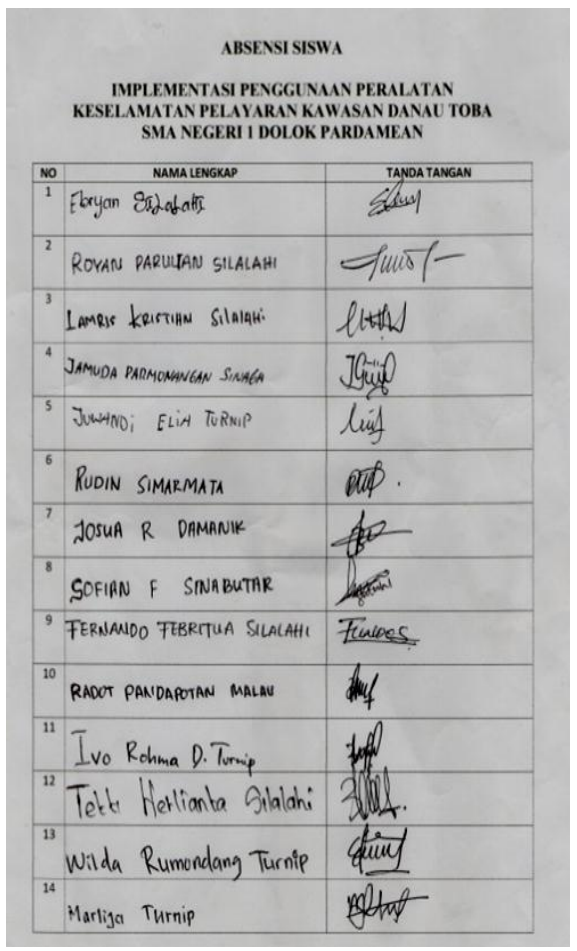

\section{Gambar 4. Absensi Mitra}

Hal ini sangat penting agar aturan - aturan dalam berlayar berdasarkan kaidah - kaidah ilmiah harus diterapkan. Selain itu pada tahap evaluasi akhir dimana diperoleh data dari hasil tes mitra yang telah dilakukan sangat penting untuk mengetahui tingkat keberhasilan kegiatan pengabdian kepada masyarakat ini. Indikator tingkat keberhasilan kegiatan ini yakni mengacu pada kriteria ketuntasan minimal pada SMA Negeri 1 Dolok Pardamean yaitu nilai 75. Dengan menggunakan program SPSS, hasil evaluasi terhadap mitra terdapat pada Tabel 1.

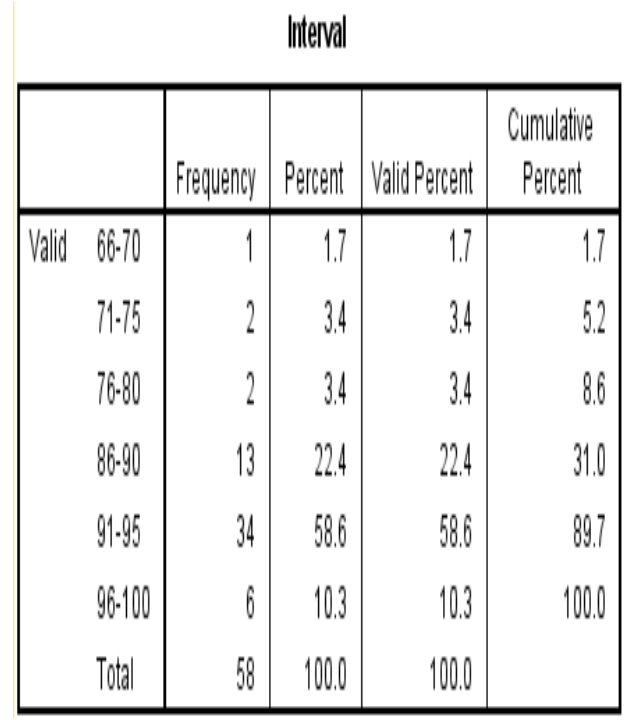

Tabel 1. Output SPSS

Berdasarkan Tabel 1, terlihat bahwa jumlah persentase mitra yang mendapatkan nilai diatas kriteria ketuntasan minimal yakni sebanyak 94,7\% dimana persentase terbesar interval nilai berada pada 91 - 95 dengan 58,6\%. Dengan demikian berdasarkan Renstra Akademi Maritim Indonesia (AMI) - Medan tahun 2018 - 2023, kegiatan pengabdian masyarakat ini dinilai berhasil karena memenuhi indikator yakni pelatihan yang menghasilkan kualitas keterampilan dalam industri pendidikan.

Di akhir kegiatan, seluruh mitra yang mengikuti pelatihan ini memperoleh sertifikat atas partisipasi untuk kegiatan ini sebagaimana terdapat pada Gambar 4. 
Available online at https://jurnal.stmikroyal.ac.id/index.php/jurdimas

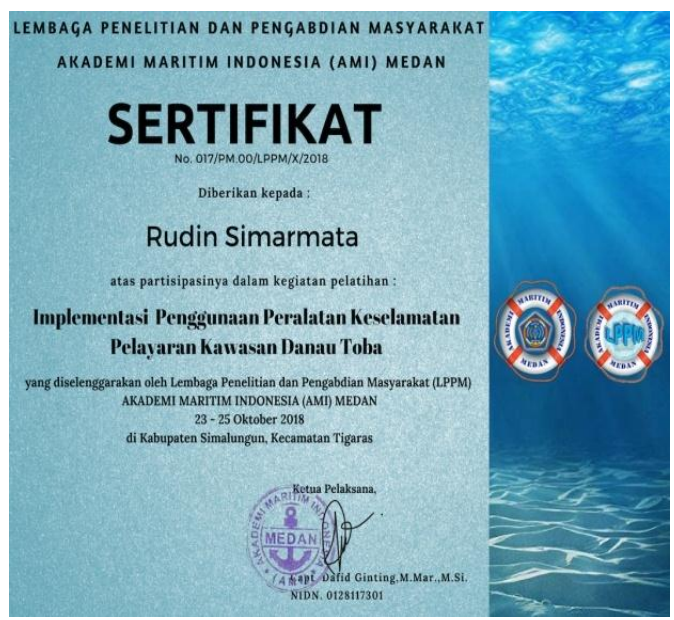

Gambar 5. Salah satu sertifikat Mitra

\section{SIMPULAN}

1. Kegiatan pengabdian masyarakat ini berhasil memenuhi indikator keberhasilan berdasarkan Renstra Pengabdian Masyarakat Akademi Maritim Indonesia (AMI) - Medan yakni pelatihan yang menghasilkan kualitas keterampilan dalam industri pendidikan

2. Timbulnya kesadaran mitra akan pentingnya aturan - aturan dalam keselamatan pelayaran

\section{UCAPAN TERIMA KASIH}

Ucapan terimakasih disampaikan kepada semua pihak yang membantu tim pengusul sehingga kegiatan pengabdian masyarakat ini dapat terlaksana dengan baik, yaitu :

1. Yayasan Akademi Maritim Indonesia (AMI) Medan yang telah membantu memberikan dana untuk kegiatan pengabdian masyarakat ini.
2. Dinas Pendidikan Pemerintah Provinsi Sumatera Utara Cabang Dinas Siantar yang telah memberikan izin tempat pelaksanaan program pengabdian masyarakat.

3. Kepala Sekolah SMAN 1 Dolok Pardamean yang telah membantu kelancaran kegiatan tim selama pelaksanaan kegiatan pengabdian masyarakat.

\section{DAFTAR PUSTAKA}

Aswab, Nanda Pratama, (2018), "Peristiwa Kapal Tenggelam Dari 2003 Hingga 2008”.

https://nasional.kompas.com/rea d/2018/06/23/15220601/15-

peristiwa-kapal-tenggelam-dari2003-hingga-2018? page $=$ all .

Diakses 22 Juli 2018.

Djamaan Arlizar, Jumardin, Ada Welem, Bustamin (2013)

"Kajian Tingkat Kesesuaian Persyaratan Sesuai Dengan SOLAS Pada Kapal - Kapal Penumpang Yang Berlayar di Selat Makassar". Jurnal Venus. 1(1) : $34-44$

Kadarisman Muh (2017) "Kebijakan Keselamatan Dan Keamanan Maritim Dalam Menunjang Sistem Transportasi Laut". Jurnal Manajemen Transportasi \& Logistik. 4(2) : 177 - 192.

Suwestian M.F., Ghalib Saladin., Utomo Setio (2015) "Implementasi Kebijakan Sistem Manajemen Keselamatan Pelayaran (Studi Di PT. Maritim Barito Perkasa Banjarmasin)". Jurnal Bisnis dan Pembangunan. 3(1): $1-5$ 
Jurdimas (Jurnal Pengabdian Kepada Masyarakat) Royal

Vol. 2 No. 1, Jan 2019, hlm. 33 - 38

ISSN 2614-7912 (Print)

DOI: https://doi.org/10.33330/jurdimas.v2i1.283

ISSN 2622-3813 (Online)

Available online at https://jurnal.stmikroyal.ac.id/index.php/jurdimas

Thamrin HM (2015) "Manajemen

Keselamatan Maritim Dan

Upaya Pencegahan

Kecelakaan Kapal Ke Titik

Nol (Zero Accident)"Jurnal

Ilmiah Widya. 3(2) : $110-$

116 